\title{
Multicore myopathy in a patient with anhidrotic ectodermal dysplasia
}

We report a patient with multicore myopathy, a rare myopathy not previously reported in the anaesthetic literature. It is characterised by a myopathy of proximal muscles which tends to follow a benign course but may be associated with a severe form of cardiomyopathy. The myopathy is related to central core disease so these patients should be considered to have a potential for developing malignant hyperthermia. Complicating this case was an associated anhidrotic type of ectodermal dysplasia resulting in the absence of sweating, febrile episodes, recurrent pulmonary infections, conical and missing teeth, scaly skin and fine, sparse hair. The patient had a scoliosis repair which was uneventful but died three weeks later following a major pulmonary aspiration while on the ward. The cause of the aspiration is thought to have been unsuspected laryngeal incompetence associated with ectodermal dysplasia, the myopathy involving his bulbar muscles and analgesic medication.

Nous décrivons la première observation de la littérature anesthésique d'un malade porteur d'un myopathie congénitale à foyers multiples. Cette affection est caractérisée par une myopathie proximale dont l'évolution est ordinairement bénigne mais que à l'occasion s'associe à une forme sévère de cardiomyopathie. Ce type de myopathie s'apparente à la myopathie à axe central et les porteurs doivent être considérés comme à risque pour l'hyperthermie maligne. Comme maladie associée aggravante, le patient souffrait de dysplasie ectodermique de type anhidrotique caractérisée par une absence de transpiration, d'épisodes fébriles, infections pulmonaires à répétitions, dents de forme coniques ou absentes, d'une peau écaillée et de cheveaux clairsemés et soyeux. Le patient subit une correction

\section{Key words}

COMPLICATIONS: $\mathrm{MH}$, myopathy;

HYPERTHERMIA: malignant;

MUSCLE: myopathy;

SYNDROMES: anhidrotic ectodermal dysplasia.

From the Department of Anaesthesia, Izaak Walton Killam Children's Hospital, Halifax, Nova Scotia.

Address correspondence to: Dr. S. Litz, Department of Anaesthesia, Izaak Walton Killam Children's Hospital, P.O. Box 3070, Halifax, Nova Scotia, Canada B3J 3G9

Accepted for publication 9th July, 1992. de scoliose sans incident mais décède trois semaine plus tard d'une pneumonie d'aspiration alors qu'il était de retour à l'étage. Comme la myopathie intéressait les muscles bulbaires et que le patient recevait une médication analgésique, on relie cette aspiration à une incompétence laryngée non diagnostiquée associée à la dysplasie de l'ectoderme.

We would like to present a case report of a patient with two unrelated disorders: multicore myopathy and anhidrotic ectodermal dysplasia. Multicore myopathy is a rare myopathy, not previously reported in the anaesthetic literature. It may be accompanied by a serious cardiomyopathy and, because this disorder is related to central core disease, these patients may have a potential to develop malignant hyperthermia. Both of these disorders may compromise airway protection.

\section{Case report}

A 15-yr boy presented for a Luque repair of his thoracolumber scoliosis which was secondary to multicore myopathy. The myopathy had resulted in reduced power in all muscle groups, but of greater severity in the proximal muscles. Creatinine kinase (CK) levels were normal. He first walked when he was two years old but due to progressive muscle weakness he had been wheelchairbound since the age of five. An echocardiogram showed him to have slight impairment of left ventricular function with a shortening fraction in the low normal range. In addition to the myopathy, the patient had anhidrotic ectodermal dysplasia. This disease had resulted in progressive flexion contractures of his elbows and knees, chronic otitis media, frequent pulmonary infections, restrictive pulmonary disease with a vital capacity of $57 \%$ predicted and $\mathrm{FEV}_{1}$ (forced expiratory volume) of $67 \%$ predicted, absence of sweating, multiple episodes of pyrexia with some resulting in febrile seizures, atypical faecies, scaling skin, and conical teeth.

He had had six previous, uneventful anaesthetics for recurrent ear problems and tendon transfers, using either halothane or isoflurane. No depolarising relaxants had been used.

The patient was premedicated with $5 \mathrm{mg}$ diazepam po, and anaesthesia induced with thiopentone $350 \mathrm{mg}$, fentanyl $100 \mu \mathrm{g}$, and atracurium $40 \mathrm{mg}$ was used as the muscle 
relaxant. Maintenance of anaesthesia was with isoflurane $0.5 \%$, nitrous oxide $66 \%$ and fentanyl. Monitors included an arterial catheter, pulse oximeter, ECG, capnometer, oxygen analyser, nasopharyngeal temperature probe, urinary catheter and peripheral nerve stimulator. A moisture exchanger (Humidivent) and fluid warmer were used for temperature conservation and a cell saver for blood conservation. Propranolol $1 \mathrm{mg}$, hydralazine $10 \mathrm{mg}$, and isoflurane were used as hypotensive agents to maintain systolic BP between 80 and $100 \mathrm{mmHg}$. Anaesthesia proved uneventful apart from one episode of hypotension, with a systolic blood pressure of $60 \mathrm{mmHg}$, occurring when the surgeon nicked an epidural vein. This episode lasted for five minutes and responded quickly to volume replacement. At the end of the procedure the patient was transferred to the ICU where the trachea was extubated while he was awake, within ten minutes of arrival. He was discharged to the ward after $11 \mathrm{hr}$.

For the first four days his postoperative course was largely uneventful but it was recorded that he had a poor cough with difficulty clearing secretions. He also experienced a lot of nausea and vomiting. On the fifth day he vomited repeatedly. During this time he received multiple doses of codeine which caused marked drowsiness. Nurses noted an increase in respiratory rate but no other evidence of distress. Later, he appeared restless and had oxygen saturations of $76 \%$. A chest $x$-ray revealed evidence of aspiration. He was transferred to the ICU, the trachea was intubated and the lungs were ventilated. His respiratory status continued to deteriorate despite therapy and he died two weeks later of severe adult respiratory distress syndrome (ARDS).

\section{Discussion}

Anhidrotic ectodermal dysplasia is a disorder caused by the abnormal development of ectodermal tissue (teeth, hair, nails, sweat glands). It is of varying severity and extent. Inheritance can be autosomal dominant (RappHodgkin form if palatal clefting is also present), recessive or X-linked recessive (Christ-Siemens-Touraine syndrome). It is characterised by a small saddle-shaped nose, frontal bossing, prominent supraorbital ridges, maxillary hypoplasia, microstomia, prominent pouting lips, small conical (peg shaped) or missing teeth and dysplastic nails. ${ }^{1,7}$ Reduced mucus production in the gastrointestinal and respiratory tracts leads to frequent respiratory tract infections, otitis media, bronchitis, dysphagia and constipation. ${ }^{3,4}$ Laryngeal incompetence, ${ }^{5}$ which may also be responsible for the recurrent chest infections, is sometimes seen. Hair tends to be fine, dry and sparse. Mental retardation occurs in $30-50 \%$. Hyperthermia due to inadequate sweating, secondary to partial or complete absence of sweat glands, is common in the anhidrotic form and results in a potential for sudden death in infancy due to hyperthermia., 4 The reported mortality is in the order of $10-54 \% .^{15}$

Problems for anaesthesia in a person with the anhidrotic type of ectodermal dysplasia include potentially difficult tracheal intubation due to multiple missing teeth and hypoplasia of the maxilla. Respiratory function needs to be assessed because of recurrent chest infections.

Laryngeal incompetence may be suspected when frequent coughing occurs with meals or can be diagnosed with a barium swallow. It makes aspiration more likely and when present a rapid-sequence induction of anaesthesia is recommended. The monitoring of intraoperative temperature is essential as these patients may develop hyperthermia due to inadequate sweating. However, in the case presented all previous anaesthetics resulted in a decrease in core temperature, so that measures for heat conservation remain important.

Multicore myopathy is a rare congenital myopathy first described by Engel et al. in 1971. It is synonymous with minicore myopathy. ${ }^{11}$ Although usually non-progressive slow progression may result in considerable disability. It is a heterogeneous group of diseases characterised by proximal muscle weakness with reduction in muscle bulk, a number of musculoskeletal abnormalities such as scoliosis, club foot, contractures and high arched palate. ${ }^{10}$ Recurrent chest infections are common and are usually due to the severity of the kyphoscoliosis. Unlike other myopathies, CK levels are usually normal..$^{9,11,12}$ It generally manifests itself in early childhood.

Multicore myopathy is thought to have an autosomal recessive inheritance although autosomal dominant varieties have been described. ${ }^{\text {II }}$ It was formerly thought that this form of myopathy had a benign course but several reports exist of its association with severe cardiomyopathies of restrictive and congestive types, some of which have been lethal., ${ }^{9,10}$ Patients with multicore myopathy have normal intelligence.

A lack of trophic influence on the innervation of muscle fihres is believed to be the cause of this myopathy. This places the disorder in a similar category with central core disease. It was formerly classified under the title of amyotonia congenita (floppy infant syndrome) and now belongs to the congenital group of structural myopathies. ${ }^{13}$ Muscle biopsies demonstrate a preponderance of type I fibres which have hypertrophied, with the presence of multiple small irregularly shaped cores resembling " $\mathrm{Z}$ " band material with an absence of mitochondria from these regions. ${ }^{10,12}$ The mitochondria that are present show a reduced level of oxidative enzyme activity. The " $Z$ " bands, which have actin filaments attached to them and form the boundaries of the sarcomere, are thought to be dependant on the close proximity of mitochondria for their integrity. 
It has been proposed that the disorder is a mitochondrial deficiency around the " $Z$ " bands resulting in the disruption of these bands. ${ }^{12}$ Multicore disease is histologically different from central core disease as the cores are small but numerous in number and situated eccentrically. Central core disease has 1-2 cores per fibre in a central position involving the entire length of the fibre. Cores are also present in type II fibres. However, some variants of central core disease have multicores present in some fibres, hence similarity does exist between the two syndromes, ${ }^{8}$ together with a similar aetiology of mitochondrial deficiency. Multiple cores are also found in other diseases, including $\mathrm{MH}$, denervation injuries and muscular dystrophies. ${ }^{9}$ Hence the presence of multicores is not pathognomonic of multicore myopathy.

The authors believe that the following recommendations should be considered in patients with multicore myopathy. All should have preoperative echocardiography due to the potential presence of cardiomyopathies. Respiratory function should be assessed due to the muscle weakness, in the presence of a kyphoscoliosis, and when recurrent chest infections are present. We believe that we underestimated the pharyngeal muscle involvement which resulted in difficulty swallowing and an inability to clear secretions. Careful assessment of swallowing and cough preoperatively and care with opiate doses and time intervals postoperatively should be taken in all patients when impaired muscle function is suspected. We do not consider that those with multicore myopathy require an anaesthetic designed specifically to avoid all $\mathrm{MH}$ triggering agents. Nonetheless, there is little experience with this disorder and as there is a close association with central core disease, both in aetiology and in some histological aspects, Palijarvi $e t a l$. and Gullotta et al. suggested that there may be a relationship between multicore myopathy and $\mathrm{MH}$. As central core disease patients are considered to have a potential for developing $\mathrm{MH}^{16,17}$ so should those with multicore myopathy. Hence the anaesthetist should be alert to the possibility of an $\mathrm{MH}$ reaction. Temperature and endtidal carbon dioxide should be carefully measured.

Although the anaesthetic in this case was largely uneventful, we believe that we underestimated the patient's ability to protect his airway. Laryngeal incompetence was almost certainly present as, on later questioning, his parents gave a history of frequent coughing with meals. It is also likely that the myopathy affected his bulbar musculature reducing airway protection. These two factors combined with administration of codeine despite drowsiness, disabled his airway reflexes sufficiently to cause aspiration.

\section{References}

1 Walpole IR, Goldblatt J. Rapp-Hodgkin hypohidrotic ectodermal dysplasia syndrome. Clin Genet 1991; 39: 114-20.
2 Sybert VP. Hypohidrotic ectodermal dysplasia: argument against an autosomal recessive form clinically indistinguishable from X-linked hypohidrotic ectodermal dysplasia (Christ-Siemens-Touraine syndrome). Pediatr Dermatol 1989; 6: 76-81.

3 Siegel MB, Potsic WP. Ectodermal dysplasia: the otolaryngologic manifestations and management. Int $\mathrm{J}$ Pediatr Otorhinolaryngol 1990; 19: 265-71.

4 Clarke A, Phillips DI, Brown R, Harper PS. Clinical aspects of $\mathrm{X}$-linked hypohidrotic ectodermal dysplasia. Arch-Dis-Child 1987; 62: 989-96.

5 Potter FC, Bowie MD. Dysphagia in hypohidrotic ectodermal dysplasia. A case report. S Afr Med J 1984; 66: $232-4$.

6 Testard $H$, Soto $B$, Wood $C$. Dysplasie ectodermique anhidrotique. Arch Fr Pediatr 1991; 48: 343-5.

7 Santos H, Cordeiro MJ, Faro Viana I, Cordeiro I. Colarinha J. Rodrigues Rapp-Hodgkin ectodermal dysplasia. Acta Paediatr Scand 1990; 79: 245-7.

8 Engel AG, Gomez MR, Groover RV. Multicore disease: a recently recognized congenital myopathy associated with multifocal degeneration of muscle fibres. Mayo Clin Proc 1971; 46: 666-81.

9 Shuaib A, Martin JM, Mitchell LB, Brownell AK. Multicore myopathy: not always a benign entity. Can J Neurol Sci 1988; 15: 10-4.

10 Magliocco AM, Mitchell LB, Brownell AK, Lester WM. Dilated cardiomyopathy in multicore myopathy. Am J Cardiol 1989; 63: 150-1.

11 Paliarvi L, Kalimo H, Lang H, Savontaus ML, Sonninen V. Minicore myopathy with dominant inheritance. J Neurol Sci 1987; 77: 11-22.

12 Edstrom L, Mair WG, Wroblewski R, Hovmoller M, Malm $G$. Type distribution of muscle fibres and their ultrastructure related to intracellular elemental composition as revealed by energy dispersive $\mathrm{X}$-ray microanalysis. A study of multicore myopathy. J Neurol Sci 1986; 76: $31-48$.

13 Korenyi-Both A, Korenyi-Both I. Congenital myopathies with "diagnostic" pathological features. J Med 1987; 18: 93-107.

14 Kalkulas BA, Morrison I, Owen ET, Kitridou R. Unusual paraspinal muscle lesions in ankylosing spondylitis. Clin Exp Neurol 1987; 23: 23-9.

15 Freire-Maia N, Pinheiro M. Precocious mortality in Christ-Siemens-Touraine syndrome. Am J Med Gen 1990; 37: 299.

16 Frank JP, Yadollah H, Butler IJ, et al. Central core disease and malignant hyperthermia syndrome. Ann Neurol 1980; 7: 11-17.

17 Eng GD, Burton S, Epstein WD, et al. Malignant hyperthermia and central core disease in a child with congenital dislocating hips. Arch Neurol 1978; 35: 189-197. 